\title{
Preliminary study of mate choice in Platypus quercivorus (Murayama) (Coleoptera: Platypodidae)
}

\author{
Masahide Kobayashi and Akira Ueda ${ }^{1, *}$ \\ Kyoto Prefectural Forestry Experimental Station, Wachicho, Kyoto 629-1121, Japan \\ ${ }^{1}$ Kansai Research Center, Forestry and Forest Products Research Institute, Kyoto 612-0855, Japan \\ (Received 28 January 2002; Accepted 10 May 2002)
}

\begin{abstract}
Platypus quercivorus (Murayama) has a complicated mating behavior similar to that of other species in Platypodidae. We observed this mating behavior in the field with a video camera, and divided the behaviors into nine phases. In successful matings, three phases required a relatively long time. As the female or the male might use the three long phases for mate choice, we compared the behavior during these phases in successful matings with that in unsuccessful matings. Five of 6 females in unsuccessful matings left the gallery in the log during the phase from the entered female's emergence until the emergence of the male's elytra. The duration of this phase correlated to times that the female walked forward and backward at the entry hole during this phase, and varied much in unsuccessful matings. These results show that the female who left early in this phase may have already decided to leave during the previous phase that was from the female's first entry into the gallery until the emergence. In contrast, the female left after the extremely long duration of this phase may have been willing to select the male but disliked by the male. Thus, both male's and female's mate choice may have occurred during these continuous 2 phases.
\end{abstract}

Key words: Ambrosia beetle, mating behavior, gallery, oak wilt, Quercus

\section{INTRODUCTION}

Male-initiated monogamy is the rule in most species in Platypodidae. In this mating system, the male awaits the arrival of a conspecific female in a gallery that he has constructed in timber before her arrival (Kirkendall, 1983). The male and the female take care of their offspring cooperatively after mating. The male guards the gallery, expels frass, and ventilates the gallery at the entry hole, whereas the female excavates the gallery, plants the ambrosia fungi that nourish the larvae and adults, oviposits, and brings frass to the male for removal. The male and female both usually stay in the gallery until emergence of the offspring. In this sort of strong bond between male and female, it is important for both to select a vigorous mate and for the female to select a male that has bored into a good reproductive resource, because prudent mate choice can be rewarded by increased fecundity (Ryan, 1997). Thus, mate choice must occur in both males and females. However, this behavior has never been investigated in Platypodidae.

Platypus quercivorus (Murayama) (Coleoptera:
Platypodidae) bores into the stems of oaks and other broad-leaved trees in Japan, Taiwan, India, Indonesia, and New Guinea (Wood and Bright, 1992). In Japan, mass mortality of oak trees attacked by this beetle has been reported in various regions on the islands of Kyushu and Honshu (Ito and Yamada, 1998). As is the case for 8 species in this family whose mating behavior has been observed (Jover, 1952; Husson, 1955; Madrid et al., 1972; Ytsma, 1988), P. quercivorus also exhibits complicated mating behavior. The male enters the gallery, followed by the female, then both back out of the gallery and change positions allowing the female to reenter the galley first. Copulation occurs when both back out until the female's abdomen is exposed (Ohya and Kinuura, 2001).

The development of modern digital video cameras has made it possible to record the behaviors of small insects. This technology made it possible for us to observe and measure the mating behaviors exhibited by $P$. quercivorus by examining videotapes. If mate choice occurs in this species, it can be assumed to occur during a long-duration phase in the mating behavior, because a prudent choice

\footnotetext{
* To whom correspondence should be addressed at: E-mail: akira@ffpri.affrc.go.jp
} 
may take a considerably longer time. To test this hypothesis, we timed the beetle's series of mating behaviors so as to identify the long-duration phases in which mate choice might occur. In the present paper, we examine this possibility by comparing the insect's behavior during the longest phases of successful matings with that of unsuccessful matings.

\section{MATERIALS AND METHODS}

The mating behavior of $P$. quercivorus was observed in Ohura Natural Park, Maizuru City, Kyoto Prefecture $\left(35^{\circ} 32^{\prime} \mathrm{N}, 135^{\circ} 23^{\prime} \mathrm{E}, 470 \mathrm{~m}\right.$ asl $)$, where mass mortality of oak trees occurred in 1997 and tree mortality was still increasing in 1999 (Kobayashi and Hagita, 2000). The mating behavior was observed from $10: 00$ to $12: 30$ on 6 July 1999 and from $06: 30$ to $09: 00$ and $15: 30$ to $17: 00$ on 7 July at entry holes which had the borings; the borings were fibers produced by beetles as they bored into the $\log$ and were distinguished from the frass which was the excrement and broken wood produced by the beetle larvae (Madrid et al., 1972). The observations were done at 21 entry holes that beetles constructed in logs of Quercus crispula Blume trees felled on 29 June, at 1 entry hole constructed in a standing tree of $Q$. serrata Thunb. ex Murray, and at 2 entry holes constructed in a standing tree of Sorbus alnifolia (Sieb. et Zucc.). We also made 1 observation at a hole where we had removed the outer bark of the log just before observation. Moreover, we tried to introduce additional females into 7 entry holes where we had observed successful matings. Other than these 25 entry holes, we observed the behavior at 13 entry holes where the introduced females had never tried to enter, and at 6 entry holes where the male residence was not confirmed and the introduced females entered but left without mating. However, data of the observations at these 19 entry holes were omitted from the analyses, because it was not certain if the introduced females contacted or communicated with males. The weather was clear during the study period, and temperatures ranged from 19.5 to $20.4^{\circ} \mathrm{C}, 18.2$ to $19.4^{\circ} \mathrm{C}$, and 22.9 to $23.7^{\circ} \mathrm{C}$.

Flying female beetles were collected with nets in the study area on the mornings of the two observation dates and used for the mating observations. The female beetles were introduced into the entry holes through the tip of a 1-ml pipette whose tip had been cut open to let the beetles pass through. A video camera was positioned above the bark surface, focusing on the entry hole; video recordings began when the female entered the gallery, and finished when both sexes were no longer visible after copulation (because both had reentered the gallery) or when the female left the gallery and did not return. A Sony DCR-TRV10 digital video camera was used for the video recordings with an $18 \times$ macro lens (Carton's R-230 Achromatic Lens). The duration of the mating behavior was measured by replaying the tape. However, we failed to time the first phase in 9 of 25 observations, because the delayed focussing made it difficult to confirm the accurate time of the female's entry. We also counted the number of times a certain behavior was repeated.

The Mann-Whitney $U$-test was used to compare the duration of a certain phase and the number of times a certain behavior was repeated between categories. The Kendall's correlation coefficient was applied to test the relationship between the duration of a certain phase and number of times a certain behavior was repeated. The StatView (ver. 5.0) computer program (SAS Institute, 1998) was used for these analyses.

\section{RESULTS}

Successful matings were observed in 19 of the 25 observations. During the mating process, a sequence of 10 different views of the beetles that occurred at the entry hole was defined. Nine periods between these views of the beetles were labeled as phases A to I (Fig. 1). Ohya and Kinuura (2001) observed that females held the ends of the male's elytra in their mandibles during phase B. However, in our study, we could not confirm that the females gripped the male's elytra, although we observed that the male backed out and pushed the female until she also backed out of the gallery. We observed conspicuous movements of the female's abdomen 7 to 8 times per second during phases $\mathrm{B}$ and $\mathrm{C}$, and of the male's abdomen 3 to 4 times per second during phases $\mathrm{E}$ and $\mathrm{F}$. The former approximately coincided with the inter-syllable intervals reported for stridulation of the female ("approaching chirp" and "spontaneous chirp"), and the latter with the inter-syllable intervals for stridulation of 


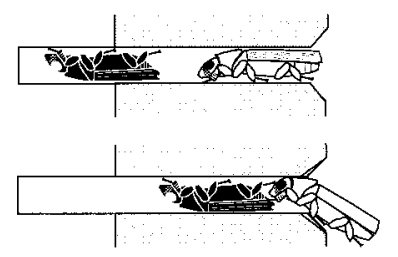

The female enters the gallery entirely.

$\downarrow$ A Not visible.

The female appears.

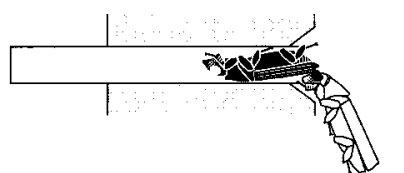

$\downarrow \mathbf{B}$

The female appears entirely, she walks forward and backward several times at the entry hole and sometimes moves her abdomen up and down 7 to 8 times per second.

The male appears.
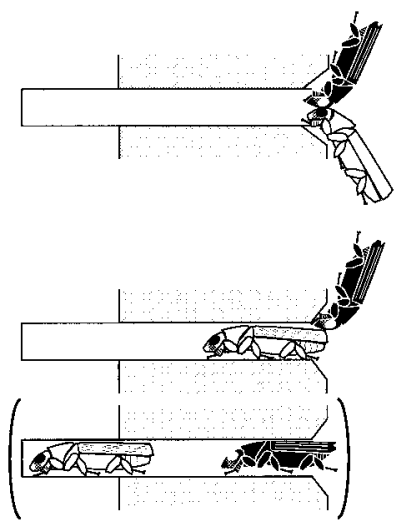

$\downarrow$ D $\begin{aligned} & \text { The female walks forward while being touched } \\ & \text { from her head to the ends of her elytra by the } \\ & \text { male's head. }\end{aligned}$ From the ends of elytra to the head, the male

$1 \mathrm{C}$ reversing out is in touch with the female's head. The female moves her abdomen 7 to 8 times per second continuously.

Both male and female emerge entirely from the gallery.

The re-entered female disappears from sight.
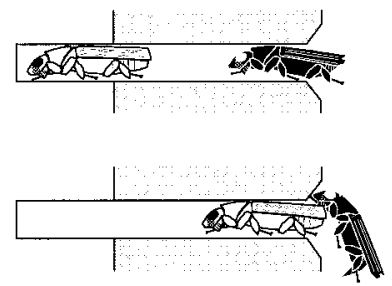

F The male begins to move his abdomen up and

$\downarrow \mathbf{E}$ down 3 to 4 times per second continuously. Following the female, the male re-enters but the ends of the male's elytra are visible.

The male begins to walk backward.

F The male waits at the entry hole continuing to move his abdomen 3 to 4 times per second.

The female protrudes her abdomen and the male pushed by the female emerges entirely while bending his abdomen.

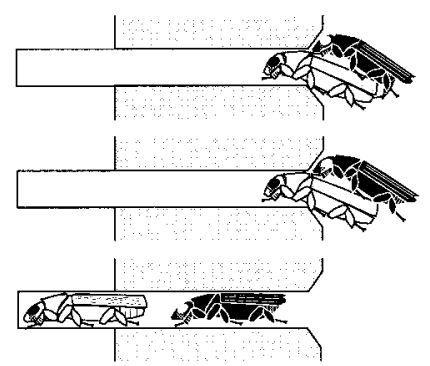

G The female walks backward.

Copulation begins.

$\downarrow \mathbf{H}$ Copulating.

Copulation ends.

I The female re-enters, followed by the male.

Both sexes disappear from sight.

Fig. 1. View at the entry hole during a successful mating. Black beetle represents male and white beetle female. The letter assigned to the phase between each pair of views appears to the right of the arrows that link consecutive phases. Observed behavior in each phase are written in the boxes. Dotted area represents the bark. Position of the beetle in the gallery is facultative except when visible at the entry hole. Turn angle of both the male and the female against the entry hole in and out of the gallery is random, although the direction of right or reverse sides of the female against the male is fixed in phases C, D, G, and H. Depth of the gallery and thickness of the bark vary at each entry hole.

the male's "in-gallery chirp" by Ohya and Kinuura (2001).

In 15 of the 19 successful matings, the beetle ran through the series of nine phases without repeating any of the ten views; we called these 15 matings "normal successful matings." The total time required for all nine phases of the normal successful matings, excluding 5 matings in which phase A was not timed averaged, $95.7 \mathrm{~s}$ with little variation $(\mathrm{SE}=10.8 \mathrm{~s})$ (Table 1). The normal successful mat- 
ings included an observation at 1 hole constructed in a standing tree of $Q$. serrata, where the mating took $111 \mathrm{~s}$ in total. Phases A, B, and E lasted the longest (Table 1). Coefficients of variations $(\mathrm{SD} /$ mean) of phases $\mathrm{A}, \mathrm{B}$, and $\mathrm{E}$ were $0.52,0.60$, and 0.77 , respectively, and were not much longer than those of other phases that ranged from 0.24 (phase F) to 0.67 (phase G).

In 3 of 4 of the remaining successful matings, the male emerged entirely after the second or third attempt by the female to touch his elytra during phase $\mathrm{C}$. The touched male disappeared into the gallery after the first or after both the first and second attempts. The durations of phase $\mathrm{C}$ in these matings were significantly longer than those of the normal successful matings $(U=0, p=0.0067)$, but the durations of the other phases were similar to those for normal successful matings (Table 1).

The fourth remaining successful mating occurred at a hole where we had removed the outer bark just before observation. Mating required 3 attempts at copulation and phase $\mathrm{G}$ lasted $165 \mathrm{~s}$ (Table 1). In this case, the male was pushed entirely out of the gallery by the female, but failed to hold onto her back with his forelegs and was separated from her during both the first and second attempts. After the second attempt, the female waited for $11 \mathrm{~s}$ with her abdomen vibrating faster than 16 times per second. (The female's abdomen moved up or down in every frame recorded by the video camera, which changed frames every $0.03 \mathrm{~s}$. Thus, the female moved her abdomen at least once per $0.06 \mathrm{~s}$.) The female then disappeared into the gallery, and the male, left alone, looked into the hole and entered again to copulate. The durations of the other phases were similar to those observed in normal successful matings (Table 1).

In 6 unsuccessful matings, the female left the gallery without copulation. In one of these observations, the elytra of the male that did not move at all were out of the gallery and visible all the time. The female touched the male's elytra with her head and moved her abdomen up and down but was not allowed to enter the gallery and finally left during phase A (Table 2, No. 1). In the remaining 5 observations, the female emerged but left during phase $\mathrm{B}$, before the male emerged (Table 2). Though there were only 2 observations in which phase A of unsuccessful matings was timed (Table 2), the duration of phase A was not different from that of the

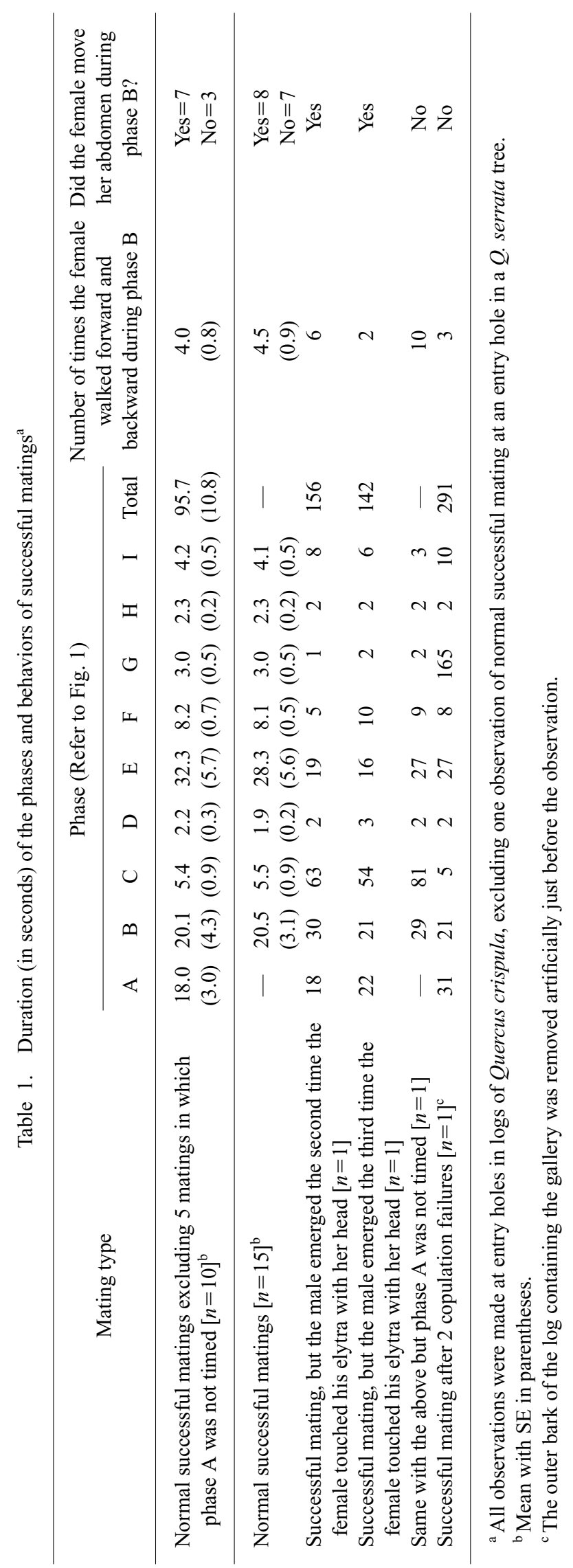


Table 2. Duration (in seconds) of the phases and behavior in the unsuccessful matings ${ }^{\mathrm{a}}$

\begin{tabular}{|c|c|c|c|c|c|}
\hline No. & $\begin{array}{c}\text { Duration } \\
\text { of phase A }\end{array}$ & $\begin{array}{l}\text { Duration } \\
\text { of phase B }\end{array}$ & $\begin{array}{l}\text { Number of times the female } \\
\text { walked forward and } \\
\text { backward during phase B }\end{array}$ & $\begin{array}{c}\text { Did the female move } \\
\text { her abdomen } \\
\text { during phase B? }\end{array}$ & $\begin{array}{l}\text { Infested } \\
\text { material }^{\mathrm{b}}\end{array}$ \\
\hline 1 & 16 & - & - & - & Log \\
\hline 2 & - & 2 & 0 & No & Tree \\
\hline 3 & - & 16 & 4 & Yes & Tree \\
\hline 4 & 35 & 30 & 4 & Yes & $\log$ \\
\hline 5 & 19 & 75 & 5 & No & $\log$ \\
\hline 6 & - & 90 & 20 & No & $\log$ \\
\hline
\end{tabular}

${ }^{a}$ All females left before the male emerged during phase B excluding No. 1, in which the female was not allowed to enter and left. The elytra of both the male and the female were visible at all times. Duration of phase A was not timed in 3 of 6 observations.

${ }^{\mathrm{b}} \mathrm{Log}$ : the entry hole bored into the log of Quercus crispula. Tree: the entry hole bored into a tree of Sorbus alnifolia.

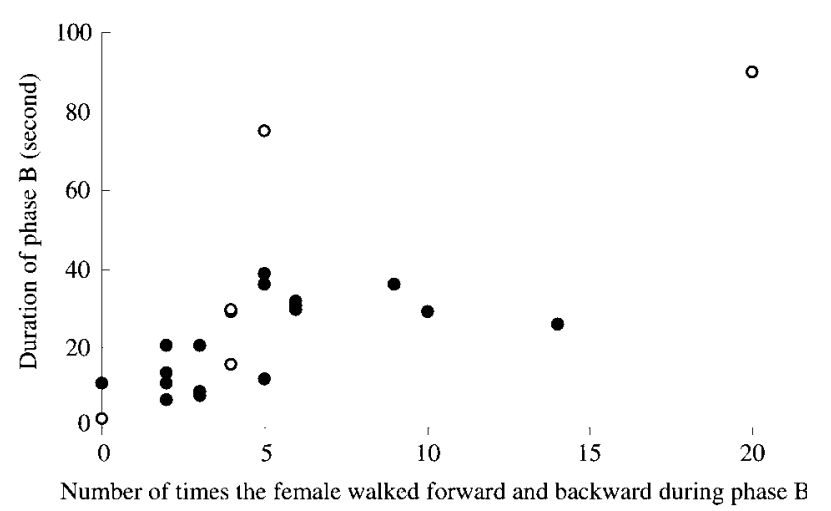

Fig. 2. Relationship between the duration of phase B and number of times the female walked forward and backward at the entry hole during phase B. There was a significant relationship by Kendall's correlation coefficient ( $\tau=0.581$, $p<0.0001)$. Solid and open symbols indicate the data of successful and unsuccessful matings, respectively.

successful matings $(U=6.5$, ns). The duration of phase B varied greatly (Table 2), but there were no significant differences between successful matings and unsuccessful matings (mean $\pm \mathrm{SE}=21.5 \pm 2.6$ and $42.6 \pm 17.0 \mathrm{~s}$, respectively. $U=27.0$, ns). The first and second shortest durations were observed at the entry holes constructed in a standing S. alnifolia tree (Table 2). The number of times that the females walked forward and backward at the entry hole during phase $\mathrm{B}$ were not different between successful matings and unsuccessful matings (mean $\pm \mathrm{SE}=4.7 \pm 0.8$ and $6.6 \pm 3.5$ times, respectively. $U=39.0$, ns). Two of 5 females performed the behavior of moving her abdomen during phase B (Table 2) as well as the females of the successful matings (10 of 19, Table 1).

There was a significant relationship between the duration of phase $\mathrm{B}$ and the number of times females walked forward and backward at the entry hole during phase B (Fig. 2). The females' moving of her abdomen during phase $\mathrm{B}$ did not relate to the duration of phase B (means \pm SE of "Yes" and "No" were $22.9 \pm 11.0$ and $28.9 \pm 27.4 \mathrm{~s}$, respectively. $U=66.5, \mathrm{~ns}$ ).

All additional females that were introduced into the entry holes where successful matings had been observed never tried to enter the galleries and struggled to walk backward in the slippery tip of the pipette. The females seemed to begin the backward walk without touching the males' body, but we could not confirm this by replaying the tape.

\section{DISCUSSION}

In the normal successful matings, long durations were observed between the female's entry into the gallery and her emergence (phase A), between the female's emergence and emergence of the male's elytra (phase B), and between the female's re-entry ahead of the male and the male's re-emergence (phase E) (Table 1). However, all 6 observations in which matings failed, the female left during phases A and B (Table 2). Thus, it seems likely that mate choice occurs during phases A and B.

The unsuccessful matings were probably caused by refusal to select a mate. In the first case, the female left during phase A, because she was not allowed to enter the gallery. Unfortunately we did not measure the depth of the gallery bored in this case, but we assume the male constructed a gallery that was too short to accept the female. It takes at least 1 day, and often 2 to 10 days, for males of other 
Platypus species to construct a gallery that can accept the female (Jover, 1952; Madrid et al., 1972; Milligan and Ytsma, 1988; Ytsma, 1988, 1989). Males that did not move at all and who's elytra were out of the gallery all the time may have been in a shallow gallery and not able to invite the female into the gallery. Thus, the mate choice may have not occurred in this case.

In the second case, the females left during phase B. The duration of phase B varied greatly (Table 2 ). In the unsuccessful matings with the shortest durations of phase $\mathrm{B}$, the female may have decided to leave during phase A. Thus, the leaving of the female without pausing resulted in a short phase B. In this case the female may have assessed not only the vigor of the male but also the quality of the gallery, because the shortest durations were observed at the entry holes constructed in a standing tree of S. alnifolia (Table 2), possibly an unsuitable tree species for the beetle's reproduction. In contrast, since the females in the unsuccessful matings, excluding those that left without stopping, behaved similar to females in the normal successful matings before leaving, the females may have wished to continue the mating behavior at the beginning of phase $\mathrm{B}$ and decided to leave during phase B.

However, in the unsuccessful matings with the longest durations of phase $\mathrm{B}$, the females may have been willing to select the male and continued the mating behavior but the males didn't emerge. In such cases, the males may have decided to reject the females during phase A or both A and B. The significant correlation between the duration of phase $\mathrm{B}$ and the number of times the female walked forward and backward during phase B (Fig. 2) suggests that both the male and female assessed the vigor of the opposite sex during the female's walking forward and backward. Thus, during phases A and B, it seems likely that the female assessed the vigor of the male and the quality of the gallery, and the male assessed the vigor of the female. However, more observations are necessary to clarify the process of mate choice. For example, observations of the mating behavior after introduction of a female into a gallery constructed by an artificially weakened male or bored into materials unsuitable/suitable for reproduction would clarify the process of mate choice in this species.

If the mate choice occurs in the long phase $\mathrm{E}$, we should find the female leaving during phase $\mathrm{F}$ but this was not observed in the present study. Further studies may show that if a female dislikes the conditions around the end of the gallery during phase $\mathrm{E}$, she will leave during phase $\mathrm{F}$, because she can assess the conditions of the gallery in detail for the first time during phase E.

In 3 successful matings, the male emerged entirely after the second or third attempt by the female to touch his elytra with her head at the entry hole, and phase $\mathrm{C}$ took significantly longer than usual (Table 1). However, the duration of this phase did not affect mating success, although it is difficult to explain why some males hesitated to emerge. Ohya and Kinuura (2001) observed that artificially silenced females awaited the emergence of males for durations ranging from $35 \mathrm{~s}$ to more than $5 \mathrm{~min}$ in phase $\mathrm{C}$ while moving their abdomen before they abandoned the mating process. However, since the males probably did not regard the silent female as a conspecific female, this is not a truly comparable instance of mate choice. If mate choice by males occurs during phase $\mathrm{C}$, we should find that females moving their abdomens would leave after a very long duration in this phase.

We observed an exceptionally successful mating that required 3 attempts at copulation when the outer-bark of the log containing the gallery had been removed (Table 1). The diameter of the entry hole is larger than that of the gallery in the sapwood beneath the bark (Inoue et al., 1998). The male that was pushed entirely out of the gallery by the female could not hold onto the female's back, because the narrowed entry hole created by debarking made the male's head protrude from the entry hole. The larger diameter of the entry hole may be important for copulation. Vibration of the female's abdomen faster than 16 times per second after the second attempt seemed to correspond to a "premating buzz" with very short inter-syllable intervals (Ohya and Kinuura, 2001). However, although the "pre-mating buzz" (Ohya and Kinuura, 2001) occurred during phase $\mathrm{C}$ in their study, the vibration of the female's abdomen was observed during phase G. The vibration may represent an irregular behavior exhibited by an irritated female who desires to copulate with a male wandering around the entry hole.

The females never tried to enter galleries that were occupied by a male and female. This fact sug- 
gests that the mated male may make physical and/or chemical signals to keep other approaching females away.

\section{ACKNOWLEDGEMENTS}

We wish to express our gratitude to Dr. Masahiko Tokoro and Mr. Hideaki Goto of the Forestry and Forest Products Research Institute, and Mr. Hiroshi Kitajima of the Institute's Kyushu Research Center for their assistance with the fieldwork.

\section{REFERENCES}

Husson, R. (1955) Sur la biologie du Coléoptère xylophage, Platypus cylindrus Fabr. Annales Universitatis Saraviensis Scientia 4: 348-356.

Inoue, M., S. Nishigaki and N. Nishimura (1998) Attack density and seasonal prevalence of two platypodid beetles, Platypus quercivorus and Platypus calamus (Coleoptera: Platypodidae) on live, dead and logged oak trees. Appl. For. Sci., Kansai 7: 121-126 (in Japanese with English summary).

Ito, S. and T. Yamada (1998) Distribution of mass mortalities of oak trees occurred in coastal areas of the Japan Sea. Forest Pests (Shinrinboueki) 47: 222-229 (in Japanese).

Jover, H. (1952) Note préliminaire sur la biologie des Platypodidae de basse-Côte d'Ivoire. Rev. Path. vég. Ent. agric. 31: 73-81.

Kirkendall, L. R. (1983) Evolution of mating systems in bark and ambrosia beetles (Coleoptera: Scolytidae and Platy- podidae). Zool. J. Linn. Soc. 77: 293-352.

Kobayashi, M. and M. Hagita (2000) Process of mass mortality of oak trees and capture of Platypus quercivorus $\mathrm{Mu}-$ rayama (Coleoptera: Platypodidae). Appl. For. Sci. 9(1): 133-140 (in Japanese with English summary).

Madrid, F., J. P. Vite and J. A. A. Renwick (1972) Evidence of aggregation pheromones in the ambrosia beetle Platypus flavicornis (F.). Z. ang. Ent. 72: 73-79.

Milligan, R. H. and G. Ytsma (1988) Pheromone dissemination by male Platypus apicalis White and P. gracilis Broun (Col., Platypodidae). J. Appl. Ent. 106: 113-118.

Ohya, E. and H. Kinuura (2001) Close range sound communications of the oak platypodid beetle Platypus quercivorus (Murayama) (Coleoptera: Platypodidae). Appl. Entomol. Zool. 36: 317-321.

Ryan, M. J. (1997) Sexual selection and mate choice. In Behavioural Ecology. 4th ed. (J. R. Krebs and N. B. Davis eds.). Blackwell Science Ltd., London, pp. 179-202.

SAS Institute (1998) StatView for PowerPC Version 5.0. SAS Institute, Cary, North Carolina, USA.

Wood, S. L. and D. E. J. Bright (1992) A catalog of Scolytidae and Platypodidae (Coleoptera), part 2: taxonomic index. Great Basin Natur. Memoirs 13: 1-1553.

Ytsma, G. (1988) Stridulation in Platypus apicalis, $P$. caviceps, and P. gracilis (Col., Platypodidae). J. Appl. Ent. 105: 256-261.

Ytsma, G. (1989) Colonization of southern beech by Platypus caviceps (Coleoptera: Platypodidae). J. Chem. Ecol. 15: 1171-1176. 